\title{
SOME NOTES ON THE SERVICE WATERS OF A RAILWAY SYSTEM. ${ }^{1}$
}

\author{
BY S. W. PARR. \\ Received March Io, Igo6.
}

\begin{abstract}
ALL of our railway systems that traverse considerable portions of the country meet with very numerous and often interesting varieties of water which must be made use of in locomotive service.
\end{abstract}

It is unnecessary to detail here the disadvantages of a poor water. Opportunity was afforded recently to verify some of the statements often quoted concerning the loss of heat due to the presence of scale of a given thickness. A test of steaming efficiency was made at the University of Illinois, ${ }^{2}$ on a locomotive having a thickness of scale averaging one-eighth of an inch. After overhauling and cleaning, a second test was made which showed a heat loss of ro. 5 per cent. due to the one-eighth of an inch scale.

This agrees closely with a comparison made some time previously on the same road. The performance sheets of one hundred and twenty locomotives were taken with reference to the consumption of coal for three months next preceding an overhauling and cleaning, and these results were compared with the coal consumption for the three months immediately following such a cleaning, with an average showing for the one hundred and twenty engines, of almost exactly ro per cent. in favor of the scale-free condition.

The annual fuel bill on one of the roads of the Middle West is approximately $\$ \mathrm{I}, 500,000$. Suppose half the locomotives on the system to be clean and working at their proper efficiency, and the other half possessed of the above average thickness of scale; 5 per cent. additional cost for fuel would represent an annual tax of $\$ 75,000$, due to this cause alone.

Duplicate this expense with another which would represent approximately the cost of overhauling and repairs, chargeable directly to the presence of scale, and we have a sum representing the annual interest at 5 per cent. on an investment of $\$ 3,000,000$. This takes no account of interest on the large number of con-

${ }^{1}$ Read at the New Orleans meeting of the American Chemical Society.

${ }^{2}$ R. R. Gazette, June 27, I8g9. 
tinuously idle engines under repair, nor of the cost of accidents or disasters due more or less directly to bad waters.

Throughout the Middle West, at least, an interesting transformation is going on in connection with the attitude of railways, in that at least five of the most extensive systems have equipped, or are in process of installing purification plants for the treatment of their service waters. This is in marked contrast to the condition existing ten years ago, when in the same region not a single plant existed for the treatment of the water to be furnished locomotives.

It should not be inferred from this fact that no interest was taken in the matter by the railways at that time. Indeed, that might well be termed the "era of soda-ash," for most of the roads were then using that or similar material in the tender tanks of their locomotives. Other substances were also used, such as trisodium phosphate, petroleum mixtures, etc., and a rather thorough trial was given to various schemes of interior treatment within the locomotive boiler, with the general result that such methods were abandoned as unsatisfactory.

Concerning interior treatment, it may be noted that in very many instances, in the case of stationary boilers, the conditions are entirely favorable for making use of the interior of the boiler for effecting a purification of the water. By analogy it would seem that a locomotive boiler could be made to serve a similar purpose, but such is not the case. Here the sum total of interior space is so small in proportion to the steaming capacity of the boiler that a very definite limit is set to the density or viscosity of the residual water. It seems pretty thoroughly demonstrated that the limitations of space and the element of time, as well as the character of the chemicals which must be used, make interior treatment, in the case of locomotive boilers, as a general proposition, inadvisable. The resulting practice, therefore, seems inevitable, viz., that of previous purification, so that the water as served to locomotives must be in the best possible condition.

As illustrating the wide variation in waters, as well as certain interesting types, the following examples are selected: A considerable number of waters have come to hand with but from 2 to 3 grains of incrusting solids, and a content of total solids not exceeding 6 or 8 grains per gallon. These waters, some twentyfive in number, are from the Illinois Central Railway Company, 
mainly in Mississippi and Louisiana, though some come from Kentucky, and one from Cairo, Illinois.

At first thought, it might be concluded that these are surface waters or waters from shallow wells in the Mississippi Delta, where the soil formation is such as to yield but little to the solvent action of the water. This, however, is only partially true. A well at Covington, Tenn., with a depth of 538 feet, shows incrusting matter to the amount of only 4.05 grains per gallon, and total solids of 5.56 grains per gallon. A well at Cairo, Illinois, 400 feet deep, shows only 5.9 grains of scaling matter, and only 8.6 grains of total solids. A number of wells from roo to 200 feet in depth show less than 5 grains of scaling matter, and less than 8 grains of total solids, while perhaps most remarkable of all is a well at Hammond, Louisiana, 2 roo feet in depth, showing scaling matter to the extent of only 5.5 grains, with free sodium carbonate amounting to 5.9 grains, the total solids being only 12 grains per gallon. Another water of this region with a depth of 825 feet has almost the same composition, viz., scaling matter 3.9 grains, free alkali 4.5 grains, and total solids less than Io grains.

It is evident under these conditions, that there is little, if any, scale formation in the boilers, and we have, therefore, an altogether different problem to deal with, namely, that of corrosion. Corroding conditions no doubt exist in many waters which produce scale, but the protection afforded by the scale prevents that action which would normally occur if the same water were continually in contact with the clean iron. The statement is occasionally met with that iron immersed in pure water may remain indefinitely without rusting. The statement is also sometimes made that the purer the water the more corrosive its action. In studying the conditions which promote the corrosion of iron, the following experiments were conducted:

In an autoclave which could be maintained under a steam pressure of one hundred pounds, there was placed a beaker of distilled water with a weighed quantity of fine wire in short pieces (card teeth). Heat and pressure were maintained for two hours with the result that there was evident corrosion. This experiment was repeated a number of times for verification. Next, the test was repeated, but the conditions were varied by first thoroughly boiling the distilled water. The amount of corrosion was greatly reduced. 
A third series of tests was made wherein the iron was added to the thoroughly boiled pure water, which had been placed in the open autoclave in which other water was vigorously boiling, so as to displace as far as possible the volume of air which would otherwise fill the spaces. The iron was then added and the autoclave sealed. Under these conditions the corrosion was practically eliminated.

This suggested another series of tests in which the same conditions as the last were maintained, but with the addition of a flask in which were pieces of marble and dilute sulphuric acid,an arrangement which would slowly and for a considerable length of time evolve carbon dioxide, but with no chance of the acid solution coming in contact with the iron, this liberation of carbon dioxide being attended, of course, by conditions of temperature and pressure of one hundred pounds per square inch, as before. Here the corrosion of the wire was very marked, much exceeding that of any of the previously outlined experiments.

Still another series of tests was suggested from these results. The same conditions were observed as in the last case, except that, instead of the flask with its marble and acid, there was substituted a shallow dish with sodium peroxide. Here, as the steaming continued, oxygen would be liberated under the conditions of temperature and pressure as before. The extent of corrosion was again very marked, being equal in amount to that produced in the presence of carbon dioxide.

Further tests were made wherein the pure water was replaced by solutions with known amounts of magnesium or calcium chloride, or nitrate and sulphate of magnesium and of iron, as also very small amounts of tannic acid, in separate tests. As might be expected, all of these solutions, with the exception of the magnesium sulphate, were strongly corroding.

In repeating all these tests, with the addition of sufficient sodium carbonate to produce slight alkalinity to the water submerging the iron, the corrosion was stopped, or at least reduced to an indeterminate amount in the time allotted for the tests.

Returning now to the non-scaling type of these southern waters under discussion, two conditions are to be noted: (a) Those waters from bayous, creeks and shallow wells hold in solution much organic matter; $(b)$ those waters from greater depths, say roo feet and more, contain, as a rule, from 2 to 6 grains per 
gallon of free sodium carbonate. Out of twenty-one waters, seven are thus provided with free sodium carbonate and seventeen are without, yet having high organic matter. Now in actual experience, in the region where these waters occur, there is some trouble from corrosion. The conclusions as to the cause are obvious. Where organic matter abounds the resulting organic acids in themselves are corroding. Where such waters mix with others having free sodium carbonate, the corroding conditions are accentuated up to the point where the sodium carbonate water is used in excess. You will see from this that there is no place given for the theory held by some, that sodium carbonate produces corrosion in boilers. It is true that a castual or perhaps superficial view of the waters above described would lead to the conclusion that the corrosion is due to the sodium carbonate naturally present in the waters, but I have yet to meet with a thoroughly authenticated case of corrosion due to the presence of free alkali in reasonably moderate amounts.

This matter of free alkali assumes a far greater importance than formerly. This brings me to a discussion of a type of water now very commonly met with farther north, more especially as far as my own experience goes, in Illinois. These waters are seldom met with at a less depth than 100 or 125 feet. They are characterized by the presence of free sodium carbonate and the absence of sulphates, at least no more than sufficient to satisfy a portion of the alkalies present. The free sodium carbonate ranges from 3 or 4 grains to 15 or 20 grains per gallon. The scaling ingredients are of course in the form of bicarbonates, and often present in amounts sufficient to place them by the ordinary classification as poor waters, or at least only fair, when, as a matter of fact, they are non-scaling and of superior quality.

At least one large area in Illinois has been developed where this water is found at a depth varying from 125 to 165 feet. With the University of Illinois as a center, it extends east and west approximately a total distance of roo miles, and north and south about 40 miles. At other scattered points, the same type is met with at varying depths. At Burnside, near Chicago, this same free alkali type occurs again at a depth of 400 feet. At Wenona, roo miles southwest, it occurs at a depth of 800 feet, but with an additional constitutent of sodium chloride amounting to 80 grains per gallon. At Carbondale again, 300 miles south of 
Chicago, the same type is met with, having 15 grains of free sodium carbonate, no sulphate of lime, and I20 grains of salt per gallon. The depth is 850 feet.

It is readily seen that in use, with this type, the water in the boiler becomes more and more impregnated with free alkali. This very soon becomes a most active precipitating reagent for the fresh incoming water, the result being that no scale but only sludge forms inside the boiler. Outside of the boiler, in the feed water, e. g., this condition does not exist; indeed the bicarbonate of lime present is in the best possible form for producing scale where only heat is applied, hence such waters scale badly in feed pipes as they approach the hot part of the boiler, as also in feedwater heaters and especially in heaters such as water-backs for household service.

One problem, and that often a serious one, presents itself in connection with this type of water, and that is the tendency to foam. A rather extensive series of tests, made in connection with a locomotive in heavy freight service on the Illinois Central, established the limit for alkaline salts of the sulphate and chloride sort as approximately 50 grains per gallon; that is, when an ordinary engine tank filled with such water has been all discharged into the boiler, the resulting concentration, bringing the ratio up to three or four times the initial amount of alkali, affords a condition to promote foaming when extra stress of work, such as a grade or greater speed, is imposed upon the engine. This tendency to foam is much enhanced by the presence of free alkali.

Now at first thought it might be concluded that the free alkali is the cause, but there is a strong probability that this is incidental and results from attending circumstances; for example, there are some evidences to show that foaming results directly from the presence of finely divided particles in suspension, and if this condition could be entirely eliminated, the presence of alkali in whatever form would be without effect so far as foaming is concerned. Turbid waters, and waters with very finely divided matter in suspension, approaching perhaps the colloidal condition, are especially susceptible to the presence of free alkali, in their tendency to foam. This is illustrated in the use of Mississippi river water in Illinois Central Railway locomotives which have previously received waters of the free alkali type from water 
stations north of New Orleans, even though such waters have what would ordinarily be considered a low content of alkali. Foaming is a common difficulty after reaching the region where the intake is from the river.

The question as to what condition actually causes foaming is of great importance. Whether finely divided particles in suspension are responsible, may not now be an element in the case, for it may be argued that boilers are never free from this condition, but it is entirely conceivable that the waters of a division might receive such efficient treatment, both chemical and mechanical, as to eliminate all of the suspended matter.

The problems connected with railway service are altogether different, therefore, from those that attend the use of stationary boilers. They involve no very profound chemical principles, and perhaps on that account have received little attention; but the industrial importance of the matter is very great, and, if for no other reason, it may perhaps be worth mentioning as an illustration of an improved and more healthy state of affairs in the industrial world, which shows itself in giving attention to wastes and greater care in small economies. When we acquire, as there are many indications that we are attempting, the habit of looking after all possible wastes and losses, from principle, the profits are more sure to look out for themselves.

UNIVERSITY OF ILIINOTS,

URBANA; ILL.

\section{A RAPID METHOD OF BABBITT METAL ANALYSIS. ${ }^{1}$}

BY H. Yockex.

Received February 23, Ig06.

THE following method of Babbitt metal analysis has been in use in this laboratory for eight or nine months, and has proved to be very satisfactory. While the principles and reactions involved are all old and well established, I have never been able to find them in print, put together in this manner and used for this purpose. The complete analysis requires from three to three and one-half hours.

Babbitt and bearing metals usually contain lead, antimony, tin and copper. Small amounts of zinc and arsenic are some-

${ }^{1}$ Read at the March meeting of the Cincinnati Section of the American Chemical Society. 